\title{
PASIËNTONDERRIGSTANDAARDE VIR VERPLEEGPRAKTYK IN ALGEMENE HOSPITALE
}

\author{
L. Coetzee, M.E. Muller, M. Vermaak
}

\section{INLEIDING}

Hospitalisasie beteken die oorgang van 'n bekende na 'n onbekende omgewing en ontketen ' $n$ behoefte aan leer en of gedragsverandering ten opsigte van sy gesondheidstoestand by die pasiënt. Dit is ' $n$ integrale deel van die verpleegkundige se onafhanklike funksie om ook in hierdie behoefte van die pasiënt te voorsien.

Navorsers dui op 'n aantal positiewe gevolge van pasiëntonderrig (Devine 1986, p 99-100) (Wilson-Barnett 1983, p 37) en dit is duidelik dat pasiëntonderrig uiteindelik sal lei tot effektiewer pasiëntsorg. Ten spyte van baie duidelike voordele word hierdie funksie van die geregistreerde verpleegkundige tot ' $n$ groot mate oorgeneem deur paramediese personeel (Brownlee, 1983 p 102). Ander navorsers bevind dat die aard en kwaliteit van pasiëntonderrig wat wel gedoen word nie na wense is nie (Pera, 1986) (Muller, 1986 p 148-150).

Hierdie ontkenning van die pasiëntonderrigfunksie deur die verpleegkundige word onder andere versterk deur 'n gebrek aan pasiëntonderrigstandaarde.

Geformuleerde standaarde wat as maatstaf van kwaliteit dien sal die verpleegkundige weereens bewus maak van haar funksie in hierdie verband.

\section{DOEL VAN DIE STUDIE}

Die doel van hierdie studie was om:

- geldige algemene

pasiëntonderrigstandaarde vir die gehospitaliseerde pasiënt in mediese- en chirurgiese afdelings te formuleer;

- 'n pasiëntonderrig evaluasie-instrument daarvolgens te ontwerp en te standaardiseer;

- die effektiwiteit van pasiëntonderrig van gehospitaliseerde pasiënte te ondersoek

- faktore te identifiseer wat die pasiëntonderrig betekenisvol beïnvloed het.

\section{LITERATUUROORSIG}

Die behoefte aan leer/gedragsverandering is volgens Redman (1981, p 11) intens by die meeste pasiënte. Kotze $(1979, \mathrm{p} 23)$ is van mening dat die sieke in sy soeke na hulp en kundigheid 'n hoë verwagting stel. Hy verwag nie net onafhanklikheid ten opsigte van sy gesondheid nie maar ook om dit in "medemenslike bemoeienis" te kry (Kotze, 1979 p 123). 'n Beplande onderrigprogram wat wetenskaplik saamgestel is, is dus noodsaaklik vir die gehospitaliseerde pasiënt.

'n Aantal aspekte is van belang met die samestelling van so 'n onderrigprogram:

- Die pasiënt se eiesoortige behoeftes asook sy gereedheid vir leer.

- Doelstellings moet fokus op die behoeftes van die pasiënt.

- Die inhoudelike word volgens elke doelstelling gestruktureer en toepaslike media word geselekteer.

- Die beplande onderrigprogram moet op wetenskaplike wyse uitgevoer word.

- Die bereiking van leerdoelstellings moet formeel beoordeel word.

Enige onderrigprogram moet op geldige standaarde gebaseer word. Daar is hoofsaaklik drie geklassifiseerde standaardveranderlikes soos deur Donabedian (1969) uitgelig:

- Struktuurstandaarde

- Proses-standaarde

- Produkstandaarde

Enigeen of enige kombinasie van die drie kan gebruik word. Elke standaard moet ook meer spesifieke kriteria insluit wat gebruik word vir meting.

In hierdie projek is algemene

pasiëntonderrigstandaarde in die vorm van 'n produkstandaard geformuleer. Die standaarde is:

1. Die pasiënt ervaar ' $n$ ingeligte periode van hospitalisasie, gegrond op effektiewe pasièntonderrig.

2. Die pasiënt demonstreer en verbaliseer begrip ten opsigte van sy fisiese omgewing tydens sy hospitaalverblyf.

\section{METODES EN TEGNIEKE}

\section{Navorsingsontwerp}

Die studie is in vier fases voltooi en 'n nieeksperimentele ontwerp is gevolg:

Fase 1: pasiëntonderrigstandaarde is geformuleer

Fase 2: 'n evaluasie instrument is ontwerp en gestandardiseer

Fase 3: die gehalte van pasiëntonderrig is vasgestel;
Fase 4: faktore wat pasiëntonderrig betekenisvol beïnvloed het, is geïdentifiseer.

STAP 1

Formulering van Pasiëntonderrigstandaarde

- Formulering van standaarde

'n Grondige literatuurstudie ten opsigte van pasiëntonderrigstandaarde is onderneem. Konsepstandaarde is deur 'n kennergroep geformuleer, aan portuurgroepe voorgelê en verfyn. Die portuurgroep het bestaan uit geregistreerde verpleegkundiges in algemene hospitale in die Oranje-Vrystaat en Natal.

- Geldigheid van standaarde

Sig- en inhoudsgeldigheid van die standaarde is bepaal met die hulp van die portuurgroepe en kliniese kundiges deur middel van 'n ordinale graderingskaal. Hierdie geldigheid is wel bevestig deur middel van 'n inhoudsgeldigheidsindekswaarde van 3,8 (skaal van 0 - 4).

\section{STAP 2}

Die Ontwerp en Standaardisering van 'n Evaluasie Instrument

- Populasie en steekproef

Twee provinsies is vir die toetsing van die instrument geselekteer. Die hospitale is volgens grootte in drie groepe gestratif waarvolgens 'n ewekansige steekproef getrek is.

Die steekproef (Tabel 1 ) is gewysig as gevolg van die volgende redes:

- beskikbaarheid van personeel het die ondersoek in klein hospitale bemoeilik;

- 'n tekort aan Zulu-sprekende veldwerkers;

- 'n verblyfprobleem vir die swart veldwerkers op die platteland en het uiteindelik so daaruitgesien:

Alle pasiënte wat vir ontslag op die navorsingsdag gereed was, is in die steekproef ingesluit totdat ' $n$ tien persent kwota vir die hospitaal bereik was.

$\begin{array}{lcccccc} & \text { Getal } & \text { Ratio } & \text { Steekpr } & \text { Getal } & \text { Ratio } & \text { Steekpr } \\ \text { Groot hospitale } & 3 & 1 & 2 & 10 & 1 & 2 \\ \text { Middelslag } & 6 & 2 & 3 & 17 & 2 & 2 \\ \text { Klein } & 23 & 8 & 0 & 16 & 2 & 1 \\ \text { Totaal } & 32 & 11 & 5 & 43 & 5 & 5\end{array}$


- Instrument

Die geldige pasiëntonderrigstandaarde is deur die navorsers as konseptuele model vir die evaluasie-instrument gebruik.

Kriteria is vanuit die standaarde geformuleer om as evalueringsveranderlikes in die instrument te dien. 'n Kontrole-lys is vir die evalueringsgradering geselekteer, naamlik ja/nee en onseker of nie van toepassing.

- Evalueringstegniek

Onderhoudvoering met pasiënte wat gereed is vir ontslag, asook die ouditering van die pasiënt se rekord is as tegnieke gebruik.

\section{- Loodstudie}

'n Loodstudie is gedoen en geringe veranderinge is aangebring aan die instrument.

\section{- Toestemming}

Toestemming vir die ondersoek is van alle owerhede verkry. Tydens die navorsing is mondelinge toestemming by elke respondent/deelnemer verkry, nadat die doel van die ondersoek asook die verloop en betrokkenheid van die respondent, aan en verduidelik is.

Veldwerkers

Geregistreerde verpleegkundiges wat die taal van die pasiënte kon praat is

aangestel, uiteindelik 'n totaal van vyf (5) Al die veldwerkers het opleiding ontvang vir die gebruik van die instrument.

\section{Geldigheid en betroubarheid van die instrument}

Inhoudingsgeldigheid is aanvaar op grond van die inhoudsgeldigheidsindeks-waarde wat deur die standaarde verkry is $(3,8)$.

Daar is gepoog om konstrukgeldigheid te bewys deur die teoretiese omgekeerde verband tussen angs en kennis met behulp van die instrument te toets. Die navorsers was van mening dat die fase van onderhoudvoering (pre-ontslag) 'n invloed op die respondente se angsvlakke kon hê, en derhalwe 'n lae angsvlakgradering ten gevolg gehad het en konstrukgeldigheid is niebewys nie.

instrument is betroubaar deur middel van interne konsekwentheid, op grond van 'n Kuder-Richardson korrelasiekoëffisient van 0,88 , bewys. Waarnemerbetroubaarheid is op grond van 'n chikwadraat korrelasie-koëffisient van 0,79 positief bewys.

\section{STAP 3}

Die evaluering van die gehalte van pasiëntonderrig vir gehospitaliseerde pasiënte in mediese- en chirurgiese afdelings

- Navorsingsmetode

Hierdie stap is gelyktydig met stap twee uitgevoer. Dieselfde metode ten opsigte van populasie, steekproef en instrument, is dus gebruik.

- Resultate en bespreking

1. Outo-biografiese resultate

- Geslag

Beide vroulike en manlike geslag was goed verteenwoordig met onderskeidelik 219 $(56 \%)$ en $175(44 \%)$ respondente.

\section{- Bevolkingsgroep}

Die bevolkingsgroep is hoofsaaklik deur blankes, naamlik $41 \%(\mathrm{~N}=162)$ en swartes, naamlik $39 \%(\mathrm{~N}=155)$

verteenwoordig. Die Indiërs het $17 \%(\mathrm{~N}=$ $66)$ en die Kleurlinge het $2 \%(\mathrm{~N}=7)$ van die totaal uitgemaak.

\section{- Ouderdomsverspreiding}

Die ouderdomverspreiding was hoofsaaklik gekonsentreerd tussen 26-40 jaar wat $27 \%(\mathrm{~N}=106)$ en 41-65 jaar wat $35 \%(\mathrm{~N}=138)$ van die groep uitgemaak het. Die oorblywende $17 \%(\mathrm{~N}=66)$ was jonger as 25 jaar en $20 \%(\mathrm{~N}=80)$ was ouer as 66 jaar.

\section{- Skoolopleiding}

$35 \%(\mathrm{~N}=138)$ van die respondente se skoolopleiding was onder standerd 6 en 'n skamele $23 \%(\mathrm{~N}=92)$ het oor standerd tien opleiding beskik. $13 \%(\mathrm{~N}=53)$ het egter oor standerd agt skoolopleiding beskik.

- Verdere akademiese kwalifikasies Die oorgrote meerderheid van die respondente, naamlik $74 \%(\mathrm{~N}=297)$ beskik nie oor verdere akademiese kwalifikasies na voltooiing van hul skoolopleiding nie. Slegs $18 \%(\mathrm{~N}=65)$ het positief op hierdie vraag geantwoord.

- Verdere kwalifikasies

$6 \%(\mathrm{~N}=23)$ van die respondente het oor 'n verdere professionele $\mathrm{kwalifikasie}$ beskik, $8 \%(\mathrm{~N}=32)$ het tegniese opleiding gehad en $2 \%(\mathrm{~N}=10)$ was studente. Die meeste respondente het nie oor verdere opleiding beskik nie.

- Taal van respondente

$37 \%(\mathrm{~N}=144)$ van die respondente kon slegs Afrikaans of 'n Swart taal praat. $28 \%$ $(\mathrm{N}=110)$ was egter albei die offisiele landstale magtig.

\section{Rede vir hospitalisasie}

Tabel 2 dui aan dat die meeste respondente, naamlik $47 \%(\mathrm{~N}=185)$ vir chirurgiese redes gehospitaliseer was. $20 \%$ $(\mathrm{N}=80$ ) het ' $\mathrm{n}$ mediese gesondheidsprobleem gehad en $15 \%(\mathrm{~N}=57)$ was vir mediese ondersoeke gehospitaliseer.

Vir $24 \%(\mathrm{~N}=96)$ van die respondente was dit hul eerste kennismaking met hospitalisasie. $75 \%(\mathrm{~N}=296)$ is egter al voorheen gehospitaliseer en redelik vertroud met omgewing en roetine.

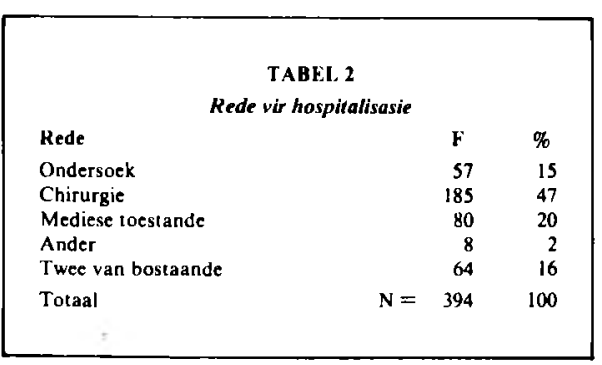

3. Pasiëntkennis

3.1 Aanvanklike voorbereiding en oriëntasie

- Fisiese oriëntasie

Dit blyk dat slegs $56 \%(\mathrm{~N}=222)$ van die respondente ten opsigte van hul fisiese omgewing net na opname in die hospitaal, georiënteer is. $33 \%(\mathrm{~N}=129)$ is glad nie georiënteer nie en die res is onseker, of slegs gedeeltelik georiënteer.

- Rede vir hospitalisasie

$90 \%(\mathrm{~N}=394)$ van die respondente toon wel insig in die rede vir hul hospitalisasie. $4 \%(\mathrm{~N}=15)$ het geen insig getoon nie en die oorblywende $6 \%(\mathrm{~N}=25)$ het onseker voorgekom, of slegs 'n vae begrip getoon.

- Prognose

$62 \%(\mathrm{~N}=245)$ van pasiënte toon insig in hul prognose. $6 \%(\mathrm{~N}=25)$ het egter geen insig in hul prognoses getoon nie en 'n totaal van $31 \%(\mathrm{~N}=121)$ was onseker of het slegs gedeeltelike insig getoon.

3.2 Pasiëntonderrig ten opsigte van chirurgie

- Pre-operatiewe voorbereiding (Tabel 2)

Slegs $46 \%(N=101)$ van die respondente het 'n vermoede of begrip gehad ten opsigte van die moontlike periode van hospitaalverblyf sonder komplikasies. Die werklike rede of doel van die operasie was aan $86 \%(\mathrm{~N}=188)$ van die respondente bekend teenoor die $8 \%(\mathrm{~N}=18)$ wat glad nie geweet het nie en $6 \%(N=14)$ wat onseker was. Slegs $29 \%(N=64)$ van die respondente het die posisie en moontlike grootte van die chirurgiese insnyding vooraf begryp teenoor $49 \%(\mathrm{~N}=107)$ wat werklik geen begrip of inligting in hierdie verband gehad het nie.

Die funksies en doel van die betrokke organe wat deur die chirurgie geraak gaan word, is aan die minderheid respondente, naamlik $46 \%(\mathrm{~N}=102)$ onderrig. $25 \%(\mathrm{~N}$ $=54)$ respondente het geen begrip van die organiese betrokkenheid gehad nie en $29 \%$ $(\mathrm{N}=64)$ was onseker.

Die onmiddellike pre-operatiewe inligting soos operatiewe skeduleringstyd, uithongering, premedikasie en skeer, kry duidelik nie genoegsame aandag tydens die onderrig van pasiënte nie. $35 \%(\mathrm{~N}=76)$ van die respondente is glad nie ingelig ten opsigte van die skeduleringstyd van die operasie nie. Slegs $42 \%(N=92)$ het geweet hoekom hul uitgehonger word en $35 \%(\mathrm{~N}=77)$ is nie aangaande premedikasie ingelig en onderrig nie. 'n Verdere $30 \%(\mathrm{~N}=65)$ het nie geweet waarom hul pre-operatief geskeer word nie.

- Postoperatiewe pasiëntonderrig Volgens Tabel 3 is dit duidelik dat hierdie
Aard

Duurte hospitalisasie Doel van operasic Chirurgiese snit Funksies van organe Tyd van operasie Uithongering Premedikasie Skeer

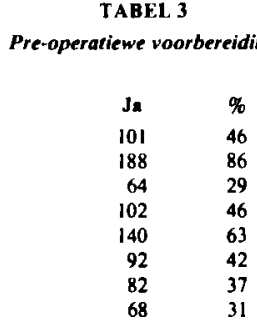

$\begin{array}{cc}\text { Nee } & \% \\ (\mathbf{N}=\mathbf{2 2 0}) \\ \mathbf{8 5} & 39 \\ 18 & 8 \\ 107 & 49 \\ 54 & 25 \\ 76 & 35 \\ 87 & 40 \\ 77 & 35 \\ 65 & 30\end{array}$

Onseker
34
14
49
64
4
41
61
87




\begin{tabular}{|c|c|c|c|c|c|c|}
\hline \multicolumn{7}{|c|}{ TABEL. 4} \\
\hline \multicolumn{7}{|c|}{ Postoperatiewe verwagtinge } \\
\hline \multirow{3}{*}{$\begin{array}{l}\text { Aard } \\
\text { Pyn }\end{array}$} & \multicolumn{2}{|r|}{ Nee } & \multicolumn{2}{|l|}{$\%$} & \multirow[b]{2}{*}{ Onseker } & \multirow[b]{2}{*}{$\%$} \\
\hline & Ja & $\%$ & & & & \\
\hline & 117 & 53 & 96 & 44 & 7 & 3 \\
\hline Dreineringsbuise & 34 & 15 & 90 & 41 & 96 & 44 \\
\hline Wond & 77 & 35 & 106 & 48 & 37 & 17 \\
\hline Urinere kateter & 47 & 21 & 68 & 31 & 105 & 48 \\
\hline Intraveneuse infusie & 88 & 40 & 83 & 38 & 49 & 22 \\
\hline Diett & 107 & 49 & 101 & 46 & 12 & 5 \\
\hline Spesiale apporaat & 13 & 6 & 57 & 26 & 150 & 68 \\
\hline Ander & 8 & 4 & 34 & 15 & 178 & 81 \\
\hline
\end{tabular}

aspek van pasiëntonderrig nie deeglik uitgevoer word nie. $44 \%(\mathrm{~N}=96)$ van die respondente is nie ten opsigte van pyn as 'n postoperatiewe verwagting onderrig nie. Slegs $15 \%(N=34)$ van die respondente is ten opsigte van verwagte dreineringsbuise ingelig of onderrig. $48 \%(\mathrm{~N}=106)$ van die respondente is nie ten opsigte van wondverwagtinge onderrig nie, teenoor die $35 \%$ $(N=77)$ wat positief in hierdie verband geantwoord het.

Onderrig ten opsigte van asemhalingsoefeninge is slegs deur $15 \%(\mathrm{~N}=33)$ positief beantwoord en beweging van ledemate is ook deur slegs $17 \%(\mathrm{~N}=37)$ as voldoende onderrig beskryf. Ander spesifieke (diagnosties-gerigte)

voorbereiding en onderrig is klaarblyklik ook afgeskeep aangesien slegs $3 \%(\mathrm{~N}=7)$ van die respondente hier positief geantwoord het.

- Postoperatiewe selfversorging

Dit blyk asof hier ook plek vir verbetering is. Die meerderheid respondente het hier "nee" op onderrig geantwoord. Onderrig ten opsigte van self was na die operasie is deur $37 \%(\mathrm{~N}=81)$ negatief ervaar, toilethulp deur $38 \%(N=84)$ negatief ervaar en self opstaan is deur $37 \%(\mathrm{~N}=$ 82) negatief beantwoord

\subsection{Pasiëntonderrig ten opsigte van} diagnostiese ondersoeke

Die doel van die ondersoeke is aan slegs $42 \%(\mathrm{~N}=53)$ van hierdie respondente verduidelik of onderrig. Slegs $8 \%(N=10)$ van hierdie respondente het insig in die moontlike newe-effekte van hierdie 104) van die respondente het glad nie geweet watter moontlike ervaring hul tydens die ondersoek/prosedure te wagte kan wees nie.

Die sorg voor, gedurende en na die prosedure is vooraf aan slegs $19 \%(\mathrm{~N}=24)$ van hierdie respondente verduidelik. ondersoeke getoon. 'n Verdere $82 \%(\mathrm{~N}=$
3.4 Pre-ontslag pasiëntonderrig

Pre-ontslag pasiëntonderrig word volgens die respondente wel gedoen. Die grootste leemte blyk hier onderrig ten opsigte van medikasie en wondversorging te wees. Dit is verder ook duidelik dat die pasiënte nie behoorlik onderrig word ten opsigte van optrede wanneer moontlike newe effekte wel voorkom nie, want slegs $4 \%(N=14)$ het positief in hierdie verband geantwoord

Positiewe terugvoer is veral ontvang ten opsigte van die fisiese verandering wat hul gaan ondergaan, werk- en sosialiseringsaanpassings, asook dieëtaanpassings en oefeninge wat hul tuis moet onderneem.

4. Pasiëntonderrig rekordhouding Hier is 'n groot leemte aangesien slegs $24 \%$ $(\mathrm{N}=95)$ van die rekords getoon het dat die pasiënt se leerbehoeftes aangeteken is Gereedheid vir leer word glad nie in ag geneem nie, aangesien slegs $1 \%(\mathrm{~N}=5)$ van die rekords hierdie aspek weerspieël.

\section{STAP 4}

Faktore wat pasiëntkennis betekenisvol beïnvloed is as volg identifiseer (Tabel 5):

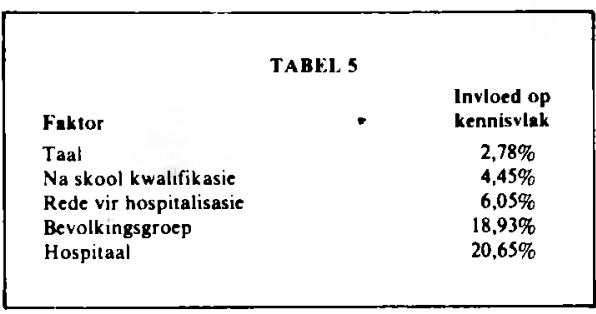

Figuur 1.

Pasiëntekennis

$(\mathbf{N}=394)$

\section{Persentasie pasiënte}

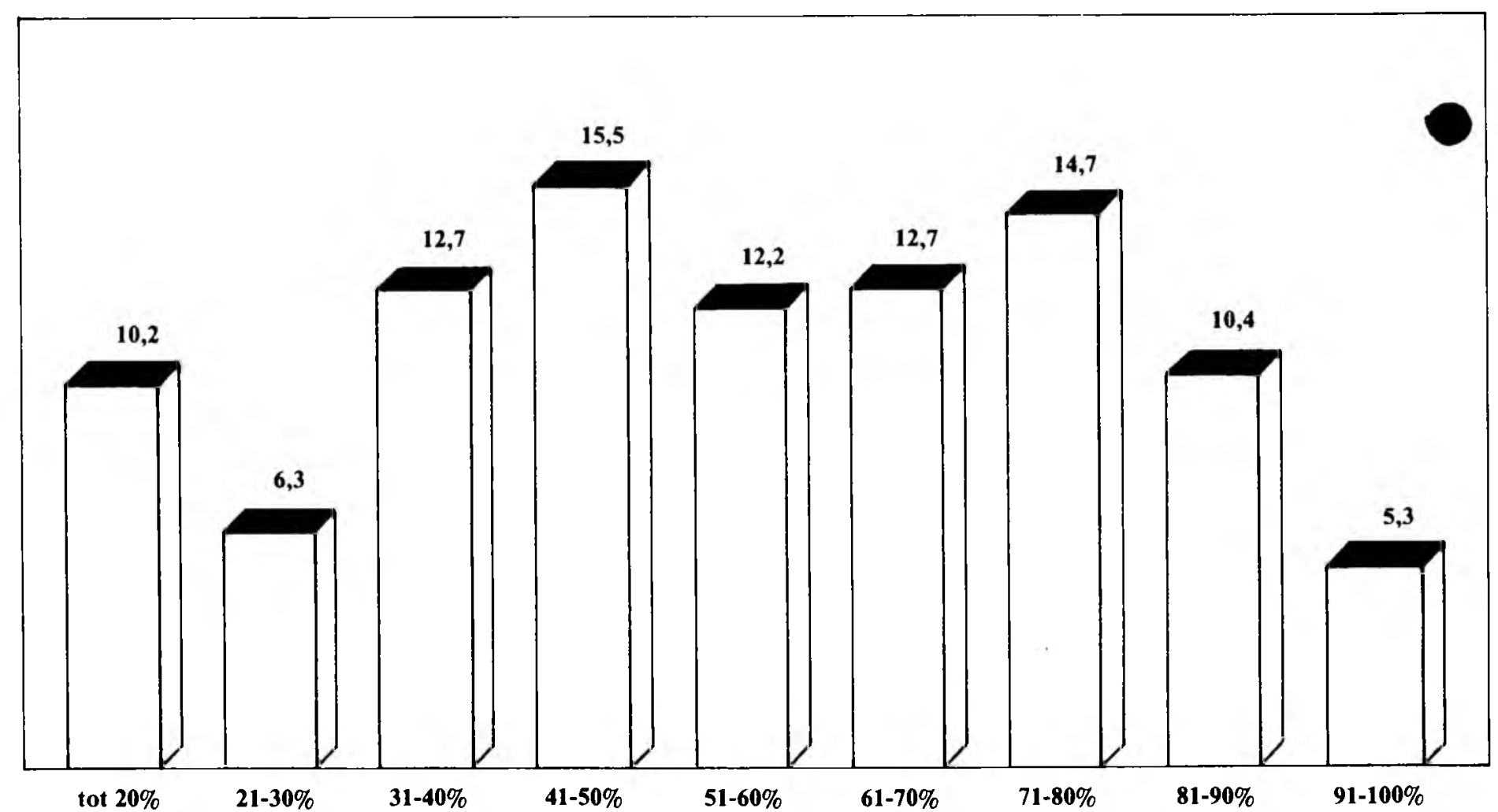

Persentasie kategorie 
Die kennisvariansie word hoofsaaklik deur die bevolkingsgroep en hospitaal bepaal, met onderskeidelik ' $18,93 \%$ en $20,65 \%$ invloed.

- Die instrument moet hersien word as gevolg van enkele items met 'n laebetroubaarheidsgradering.

\section{GEVOLGTREKKINGS}

\section{- Pasiëntkennis}

Dit is duidelik dat die respondente se vlak van kennis ontoereikend is om aan die standaard te kan voldoen. Slegs $13 \%$ van respondent het 'n vyftig persent kennisvlak behaal (Figuur 1). Die gegewens verkry uit hierdie stap van die navorsing is in die vorm van waarskynlikheidstabelle saam met die instrument beskikbaar.

\section{SLOT}

$\mathrm{Na}$ aanleiding van die waarnemerbetroubaarheidsyfers van elke item, is die instrument aangepas om probleme uit te skakel. Daar word aanbeveel dat die hersiene instrument hertoets word.

Nogtans is die totale betroubaarheid en geldigheid goed genoeg om die gebruik aan die instrument aan te beveel.

- Hierdie studie is deur die Raad vir Geesteswetenskaplike navorsing en die Suid-Afrikaanse Verpleegstersvereniging finansier. Menings uitgespreek is nie noodwendig die van hierdie instansies nie. Dank ook aan alle owerhede in die OranjeVrystaat en Natal wat toestemming verleen het vir die uitvoer van die studie in hul dienste, asook Mev. E. de Groot van die "Centre for Applied Social Studies, Universiteit Natal, wat die dataverwerking gedoen het.

\section{BIBLIOGRAFIE}

Brownlee E.B.I. (Samesteller) 1983. Die sustersin-bevel van hospitaalsale - 'n waardebepaling. Pretoria: Unisa

Donabedian A. 1969. Medical Care Appraisal - quality and utilization. A guide to Medical Administration. New York: American Public Health Association.

Kotze W.J. 1979. Begeleiding in die Verpleegkunde. Pretoria: S.A.V.V

Muller M.E. 1986. Kwaliteitsversekering in 'n kardio-torakale verpleegeenheid.

Verhandeling: Unisa (Ongepubliseerd).

Pera S.A. 1986. Nursing in the private health services in the RSA: a profile of professional practice. D.Cur Proefskrif: UPE (Ongepubliseerd).

Redman B.K. 1981. Issues and Concepts in Patient Education. New York: Appleton-Century-Crofts.

Wilson-Barnett B.A., Osborne J. 1983. Studies evaluating patient teaching: implications for practice. International Journal of Nursing Studies. Vol. 20(1), 33-44. 